\section{Chilling Enhances Cane Elongation and Flowering in Primocane-fruiting Blackberries}

\author{
Jose Lopez-Medina ${ }^{1}$ and James N. Moore ${ }^{2}$ \\ Department of Horticulture, University of Arkansas, Fayetteville, AR 72701
}

Additional index words. Rubus sp., brambles, apical meristem, flower differentiation, greenhouse culture

\begin{abstract}
Root cuttings of A-1836, APF-13, and NC194 primocane-fruiting (PF) blackberry (Rubus subgenus Rubus) genotypes were dug from the field on 31 July 1997 and stored in plastic bags at $2^{\circ} \mathrm{C}$ for 32 days. On $1 \mathrm{Sept}$. freshly dug root cuttings, along with the cold-treated ones, were planted in pots, which were kept in a lath house for 4 weeks and then moved to a heated greenhouse under natural daylength. Cold-treatment hastened emergence of all genotypes. Transition from vegetative to floral phase was first observed in cold-treated A-1836 and APF-13 at the fifth node, with floral appendages clearly evident in both genotypes at the seventh node 45 days after planting (DAP). Bloom started on 26 Nov. and 5 Dec. 1997 and the first fruits were picked on 10 and 25 Jan. 1998 in cold-treated APF-13 and A-1836, respectively. Plants of cold-treated NC194 and of all non-cold-treated genotypes remained stunted with rosetted leaves, showing no signs of floral initiation until 150 DAP. These findings show that exposure to chilling prior to shoot emergence greatly promotes flowering in PF blackberries, and may have application in greenhouse culture of blackberry.
\end{abstract}

The importance of chilling in the control of flower initiation in some plants has long been recognized. In many species, chilling acts merely as an inductive factor that enhances initiation of flower primordia after the plants are exposed to temperatures more favorable for growth (Bernier et al., 1981). Within $R u$ bus, particularly in primocane-fruiting red raspberries (Rubus idaeus L.), exposure to low temperatures hastens flowering (Privé and Sullivan, 1991; Takeda, 1993; Vasilakakis et al., 1979b, 1980; Williams, 1960). Floral induction by cold temperatures has been associated with increased activity of gibberellin-like substances, but it is unclear whether gibberellins contribute directly to flower induction in red raspberry (Vasilakakis et al., 1979a).

In blackberry, the primocane-fruiting (PF) character is not as well-developed as in the raspberry (Moore, 1984). Recently, however, a gene for PF has been incorporated into tetraploid blackberry germplasm (Ballington and Moore, 1995). The intensification of the PF trait in blackberry to the degree it is now developed in raspberry could result in revolutionary possibilities in blackberry culture

Received for publication 28 Sept. 1998. Accepted for publication 26 Jan. 1999. Published with the approval of the Director, Arkansas Agricultural Experiment Station, as manuscript \#98072. The cost of publishing this paper was defrayed in part by the payment of page charges. Under postal regulations, this paper therefore must be hereby marked advertisement solely to indicate this fact.

${ }^{1}$ Currently a Postdoctoral Research Associate in the Agronomy Dept., Univ. of Arkansas, Fayetteville, AR 72701 .

${ }^{2}$ Distinguished Professor Emeritus ; to whom reprint requests should be addressed.
(Moore, 1997). In previous experiments under greenhouse conditions, some PF genotypes propagated from root cuttings collected from the field in winter or early spring initiated flower buds as soon as the canes had formed five nodes; however, when the plants were left in the field, floral initiation did not occur until the canes had produced at least 20 nodes (Lopez-Medina et al., 1999).

We postulated that chilling can enhance flowering in PF blackberries as well as PF raspberries. If this assumption is correct, offseason production might be possible in protected environments or warm climates. The objective of this research was to study the effect of low temperature on cane elongation as well as on the onset of floral initiation and subsequent differentiation of flower parts in summer collected plant material of PF blackberry selections from the Arkansas breeding program.

\section{Materials and Methods}

Root cuttings (5.0 to $7.5 \mathrm{~cm}$ long) of A1836, APF-13, and NC194 PF blackberries growing in the field at the Arkansas Agricultural Experiment Station, Fayetteville, were collected on 31 July 1997 and stored in plastic bags at $2{ }^{\circ} \mathrm{C}$ for $768 \mathrm{~h}$. On 1 Sept., additional root cuttings were collected from the field and, along with the cold-treated ones, were immediately planted either in 3.8 -L plastic pots or in metal trays filled with Sunshine LC1 mix (Sungro Horticulture, Bellevue, Wash.) amended with Osmocote 14N-4.2P-11.6K (Scotts-Sierra Horticultural Products, Marysville, Ohio) at $100 \mathrm{~g}$ per $0.06 \mathrm{~m}^{3}$ of compressed potting soil. Three or 24 root cuttings were stuck per pot or metal tray, respectively. The cuttings were kept in a lath house for 4 weeks $\left(27.5^{\circ} \mathrm{C}\right.$ and $15.2^{\circ} \mathrm{C}$ mean daytime maximum and nighttime minimum temperatures for that time period, respectively) and then transferred to a greenhouse with 30 ${ }^{\circ} \mathrm{C}$ day $/ 18^{\circ} \mathrm{C}$ night temperatures and natural daylength. Plants in metal trays were intended for bud sampling at regular intervals for observation under a dissecting or scanning electron microscope (SEM), while those in pots were allowed to grow until fruit harvest. Bud sampling began $45 \mathrm{~d}$ after planting (DAP), with subsequent samplings every $15 \mathrm{~d}$ thereafter up to $90 \mathrm{DAP}$, and a final sampling 150 DAP. Plants were sorted, according to their growth stage, into three-, five-, seven-, and nine-node plants at each sampling date. Five terminal buds of each treatment combination were sampled each time.

The plant material was fixed and prepared for SEM observation as previously described (Lopez-Medina et al., 1999). After criticalpoint-drying and sputter coating with gold, buds were observed on an ISI-60 scanner (Intl. Scientific Instruments, Mountain View, Calif.) at $30 \mathrm{kV}$. At each sampling, the developmental stage of each bud was quantified on a 1 to 10 scale as described by Lopez-Medina et al. (1999) and Takeda and Wisniewski (1989). Growth, expressed as number of nodes and cane height, was also recorded on each sampling date in both growing containers.

The experimental layout was a $3 \times 2$ factorial, with three PF blackberry selections (genotypes) as one factor and two temperature regimes (with and without chilling) as the other factor, with the treatment combinations arranged in a completely randomized design replicated four times. Each replication consisted of either one pot with three plants (due to excessive growth, only one plant per pot was allowed to grow $60 \mathrm{DAP}$ ) or a tray with 24 plants. The data were analyzed separately for each container type by sampling date using the general linear model procedure of SAS (SAS Institute, Cary, N.C.) for analyses of variance. The values for the developmental stage of sampled buds were analyzed by the nonparametric Jonckheere-Terpstra (JT) test using the frequency procedure of SAS. Means were separated by Fisher's LSD test at $P \leq 0.05$.

\section{Results}

Significant genotype $\times$ chilling interaction was observed for time to shoot emergence from the soil in pot-grown plants (Fig. 1). Cold-treated A-1836 and APF-13 produced shoots in $<2$ weeks, as opposed to almost 3 weeks for non-cold-treated root cuttings of the same genotypes. Growth of cold-treated NC194 was similar to that of non-cold-treated A-1836 and APF-13, and at least 5 weeks were required for non-cold-treated NC194 plants to emerge. A similar trend in shoot emergence was observed in tray-grown plants, except that main effects of genotype $(P \leq 0.001)$ and chilling treatment were significant $(P=0.007)$, but interaction was not (data not shown). In this case, shoots began to emerge from coldtreated root cuttings 16 DAP, whereas noncold-treated emerged 31 DAP. Among geno- 


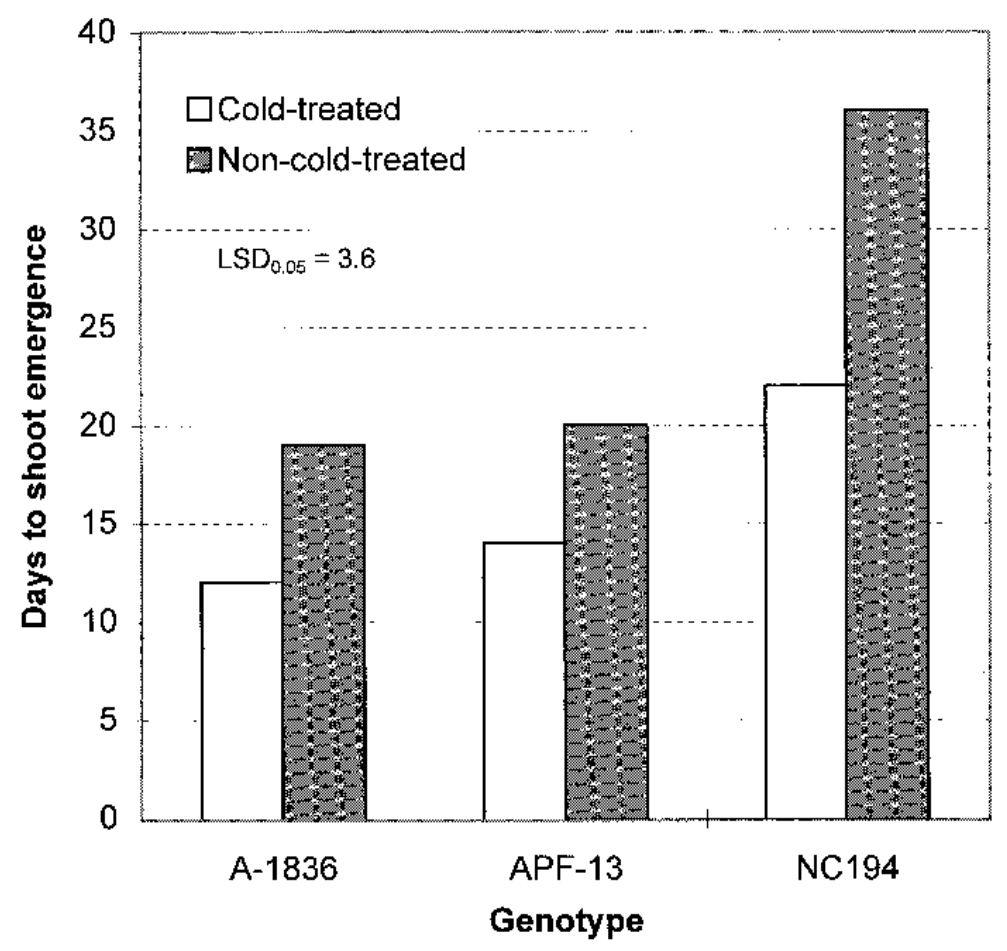

Fig. 1. Effect of cold treatment of root cuttings of three primocane-fruiting blackberry genotypes on time to shoot emergence when grown in plastic pots under greenhouse conditions. Cold-treated cuttings were collected from the field on 31 July 1997 and stored at $2{ }^{\circ} \mathrm{C}$ for $32 \mathrm{~d}$. Non-cold-treated cuttings were collected on 1 Sept. 1997 and planted immediately. Each value is the mean for 12 plants.

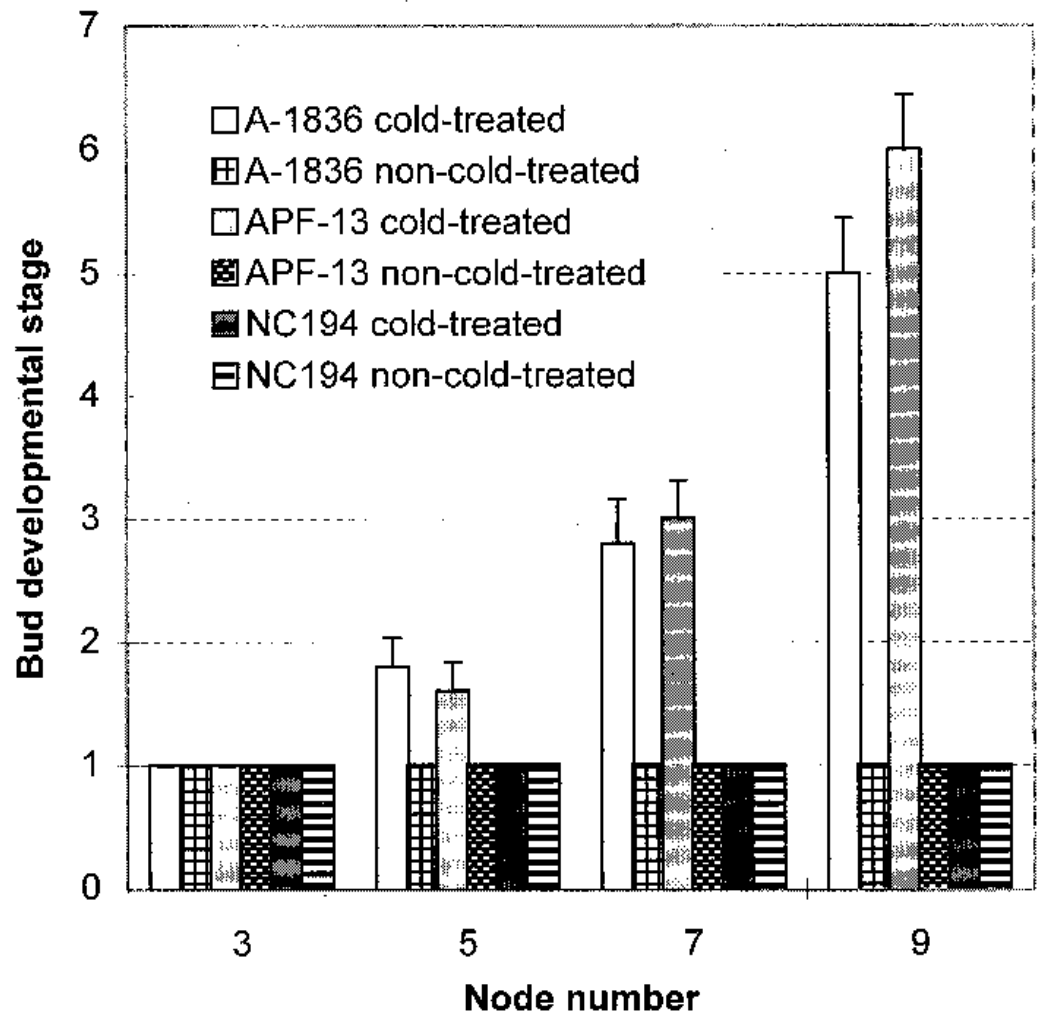

Fig. 2. Effect of cold treatment of root cuttings of three primocane-fruiting blackberry genotypes on flower bud development. Cold-treated cuttings were collected from the field on 31 July 1997 and stored at $2{ }^{\circ} \mathrm{C}$ for $32 \mathrm{~d}$. Non-cold-treated cuttings were collected on 1 Sept. 1997 and planted immediately. Cuttings were planted 1 Sept. 1997 in metal trays, kept in a lath house for 4 weeks, and then moved to a heated greenhouse under natural daylength. Flower bud development was measured on a 1-to-10 scale, where 1 = vegetative meristem, 2 = transition from vegetative to floral phase -bract primordia evident- [See Lopez-Medina et al. (1999) for complete description of stages]. Each value is the mean for 20 plants. types, NC194 emerged 39 DAP as opposed to 15 and 16 DAP for A-1836 and APF-13, respectively.

The change from vegetative to floral phase was first detected 45 DAP in terminal buds of five-node, cold-treated A-1836 and APF-13 plants (Fig. 2), when both genotypes had attained over $6 \mathrm{~cm}$ of height. This event was characterized by a "doming" and broadening of the previously flat terminal meristem and evidence of bract primordia. Terminal buds of seven-node plants sampled on the same date had initiated sepals and, in a few cases, sepals had started to become three-lobed. By the time canes of cold-treated A-1836 had produced nine nodes (60 DAP), petal primordia were clearly differentiated and the sepals began to enclose the central receptacle. At the same growth stage, cold-treated APF-13 showed a more elongated central receptacle at the terminal bud of the $A_{1}$ inflorescence axis (Takeda, 1987), with initiation of stamen and gynoecial primordia. At 75 and 90 DAP, flower development continued normally (Lopez-Medina et al., 1999) in cold-treated A-1836 and APF-13.

Pot-grown plants of cold-treated APF-13 and A-1836 started to bloom on 26 Nov. (86 DAP) and 5 Dec. (95 DAP) 1997, respectively, with harvest of the first fruits on 10 Jan. (131 DAP) and 25 Jan. (146 DAP) 1998 for these genotypes, respectively. Flower bud primordia were not observed in cold-treated NC194 or in any non-cold-treated genotypes until 150 DAP, when the canes had formed at least 15 nodes. Such plants remained stunted and formed rosettes with very short internodes (Fig. 3); however, cold treatment did not affect the number of nodes formed (data not shown).

Although we had not intended to determine the effect of type of container in which the plants were grown, plants given similar treatments were more elongated and produced more nodes when grown in pots than when grown in trays. With the exception of node number in pot-grown plants, cold-treated A1836 and APF-13 were always significantly different from those for non-cold-treated plants within a particular container type at each sampling date (data not shown).

\section{Discussion}

Exposure of root cuttings to chilling promoted earlier shoot emergence in all three primocane-fruiting blackberry selections (Fig. 1). Chilling also hastened floral initiation and subsequent differentiation of flower parts in A-1836 and APF-13 (Fig. 2), favoring early cropping. Cold-treated A-1836 and APF-13 produced canes with longer internodes (but not necessarily more nodes) than did corresponding non-cold-treated plants (data not shown). These results agree with similar reports on primocane-fruiting red raspberry. Takeda (1993) found that plants of 'Heritage' exposed to 775 chilling units (CU) flowered $130 \mathrm{~d}$ after being returned to a heated greenhouse; canes were $1.5 \mathrm{~m}$ long with 38 nodes. In contrast, unchilled plants did not flower within $240 \mathrm{~d}$, and canes were only $3.3 \mathrm{~m}$ long with more than 90 nodes. Vasilakakis et al. (1980) 


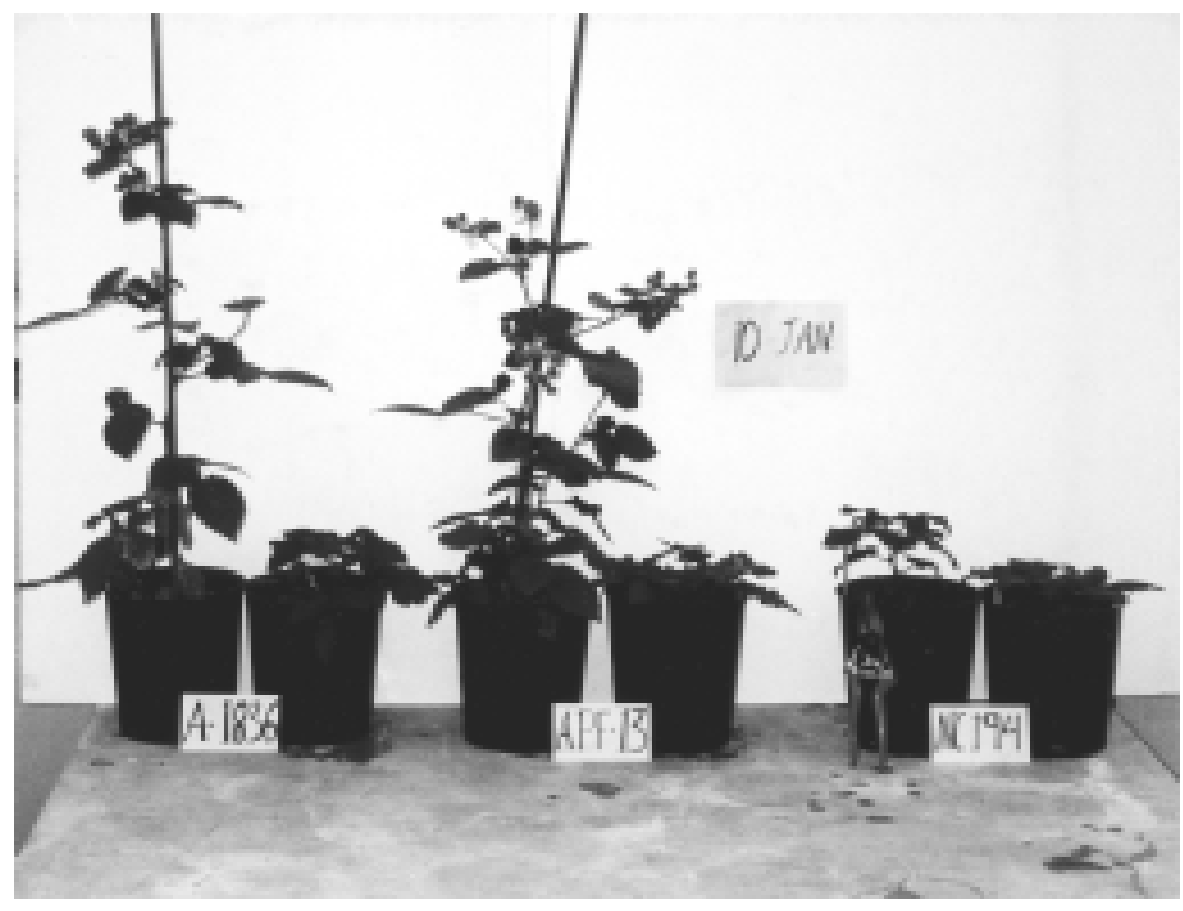

Fig. 3. Plants of three primocane-fruiting blackberry genotypes (A-1836, APF-13, and NC194) propagated from root cuttings collected 31 July 1997 and planted 1 Sept. 1997. For each genotype, the plant on the left originated from root cuttings that received 768 chilling units $(\mathrm{CU})$ prior to planting, whereas the plant on the right received no $\mathrm{CU}$.

obtained somewhat similar results with the same cultivar. Plants with 10 to 12 and 14 to 16 nodes exposed to $600 \mathrm{CU}$ flowered when they reached 32 and 28 nodes, respectively, whereas plants not exposed to cold did not flower until the canes reached 80 nodes. Privé and Sullivan (1991) compared actively growing plantlets of tissue-cultured 'Heritage', 'Ruby,' and 'Redwing' red raspberries from the greenhouse with cold-stored plantlets. Once potted and placed outdoors, canes of the cold-stored plants were longer with longer internodes, sometimes reaching twice the length of greenhousegrown plants, but the number of nodes was not affected by chilling. However, Finn et al. (1994) found that cold treatment reduced cane length of 'Redwing' plants from tissue culture. In a study conducted in Wisconsin with 'Heritage' red raspberry, floral initiation was evident in cold-treated plants by 27 Mar., but no buds had developed sepals in non-cold-treated plants on the same date (Vasilakakis et al., 1979b).

Before flowering can occur, PF red raspberry plants need either to attain a minimum size or produce a minimum number of leaves (Hoover et al., 1989; Williams, 1960), but temperature is a major factor that can modify these prerequisites. For instance, when root buds of 'Heritage' and 'Fallred' were exposed to chilling, the earliest stage of flower induc- tion occurred when the canes reached 20 nodes (Vasilakakis et al., 1979b). The same principle seems to be applicable to PF blackberries; however, our data show that flower bud induction can be attained at a much earlier stage than in PF raspberries. In our study, the prevailing temperatures in the greenhouse ranged between $30{ }^{\circ} \mathrm{C}$ day and $18^{\circ} \mathrm{C}$ night, a factor that might have also contributed to early flowering. High temperatures (such as those provided by plastic tunnels) reportedly promote rapid growth of canes in PF red raspberries, causing the canes to reach the flowering stage earlier (Hoover et al., 1989). Another factor that might be involved in early flowering in the present study is the size of container in which the plants were grown; pot-grown plants were more elongated and produced a greater number of nodes than did those grown in trays (data not shown), possibly because trays restricted root growth (where soil was no deeper than $6 \mathrm{~cm}$ ), as noted previously for field- and pot-grown plants of the same genotypes (Lopez-Medina et al., 1999). Why plants of NC194 did not initiate flower buds in response to CU, as A-1836 and APF-13 did, remains unclear. The occurrence of stunted plants with rosetted leaves (Fig. 3) might be an indication that NC194 has higher chilling requirements.
This study has presented evidence that PF blackberries can flower in response to chilling as do PF raspberries. Root cuttings collected in the summer and exposed to a period of low temperature can give rise to plants capable of producing a crop in $<5$ months. The response, however, is greatly genotype-dependent. These results may have applicability to blackberry culture under greenhouse conditions.

\section{Literature Cited}

Ballington, J.R. and J.N. Moore. 1995. NC194 primocane-fruiting thorny erect tetraploid blackberry germplasm. Fruit. Var. J. 49:101-102.

Bernier, G., J.-M. Kinet, and R.M. Sachs. 1981. The physiology of flowering. vol. 1. CRC Press, Boca Raton, Fla. p. 69-81.

Finn, C., M. Warmund, and C. Starbuck. 1994. Vegetative growth and fruit yield of three types of micropropagated 'Redwing' red raspberry nursery stock. HortTechnology 4:359-361.

Hoover, E., J. Luby, D. Bedford, M. Pritts, E. Hanson, A. Dale, and H. Daubeny. 1989. Temperature influence on harvest date and cane development of primocane-fruiting red raspberries. Acta Hort. 262:297-303.

Lopez-Medina, J., J.N. Moore, and K.S. Kim. 1999. Flower bud initiation in primocane-fruiting blackberry germplasm. HortScience 34:132136.

Moore, J.N. 1984. Blackberry breeding. HortScience 19:183-185.

Moore, J.N. 1997. Blackberries and raspberries in the southern United States: Yesterday, today and tomorrow. Fruit Var. J. 51:148-157.

Privé, J.P. and J.A. Sullivan. 1991. Performance of tissue-cultured primocane-fruiting red raspberries following chilling. HortScience 26:590592.

Takeda, F. 1987. Some factors associated with fruit maturity range in cultivars of the semi-erect, tetraploid thornless blackberry. HortScience 22:405-408.

Takeda, F. 1993. Chilling affects flowering of primocane-fruiting 'Heritage' red raspberry. Acta Hort. 352:247-252.

Takeda, F. and M. Wisniewski. 1989. Organogenesis and patterns of floral bud development in two eastern thornless blackberry cultivars. J. Amer. Soc. Hort. Sci. 114:528-531.

Vasilakakis, M.D., B.H. McCown, and M.N. Dana. 1979a. Hormonal changes associated with growth and development of red raspberries. Physiol. Plant. 45:17-22.

Vasilakakis, M.D., B.H. McCown, and M.N. Dana 1980. Low temperature and flowering of primocane-fruiting red raspberries. HortScience 15:750-751.

Vasilakakis, M.D., B.E. Struckmeyer, and M.N. Dana. 1979b. Temperature and development of red raspberry flower buds. J. Amer. Soc. Hort. Sci. 104:61-62.

Williams, I.H. 1960. Effects of environment on Rubus idaeus L. V. Dormancy and flowering of the mature shoot. J. Hort. Sci. 35:214-220. 